\title{
The Governance and Analysis on Migration in the Frontier Region of Yunnan
}

\author{
Gu He Fan lin \\ School of Public Administration, Yunnan University of Economics and Finance, \\ Kunming, P. R. China, 650221 \\ (ghguhe@163.com; Lenne-lin@163.com)
}

\begin{abstract}
Cross-border migration in border areas of Yunnan has already been the emphasis and difficulty of social governance. On the one hand, it promotes the prosperous development of border trade, but on the other it causes a series of social problems. At present, there are three different forms of cross-border population movements: crossborder movement of border residents, personnel from other province, and foreigners. To solve the problems in crossborder population movements, we need to establish regional cooperation mechanisms on the management of crossborder population movements and to strengthen the borders and non-native floating population management
\end{abstract}

Keywords: Cross-border, Population Movement, Governance

\section{Introduction}

Yunnan province is located in the southwestern border of China, where the social and cultural environment and geographical position is very special. In the early 1990s, China implemented the national development strategy of opening up border areas. With the rapid development of China's social economy, Yunnan border became the leading edge of the foreign social and economic activities. Meanwhile, cross-border population movement was more frequent in the border areas of Yunnan, showing a development trend on rising population and varied forms. From January to October in 2013, entry-exit persons in Yunnan Port reached 23.32 million, with a year-on-year growth of $16.3 \%$. Including the exit persons reached 11.514 million, with a year-on-year growth of $15.9 \%$; the entry persons reached 11.806 million, with a year-on-year growth of $16.6 \%$. Cross-border population movement in the frontier region of Yunnan has already been the emphasis and difficulty of social governance. On the one hand, it promotes the prosperous development of border trade, but on the other it causes a series of social problems.

\section{Cross-border migration in border areas of Yunnan}

Yunnan, having a $4060 \mathrm{~km}$ border, borders Burma, Vietnam and Laos. As early as over 2000 years ago, Yunnan was the important portal that Chinese mainland had economic and cultural contacts with Southeast Asia, South Asia and Arab. There are four primary land types on foreign channel of Yunnan: predominantly Kunming-Bangkok highway as SinoLaos(Thai) channel, Kunming-Honghe highway as Sino-Vietnam channel, Sino-Burma channel and Sino-India channel. Moreover, there are twelve national first-class land, water and air ports, eight national second-class ports in Yunnan province. Except Kunming airport and Puer shipping port, other ports are distributed in the zones along the borders. Meanwhile, there are more than 80 border channels and 100 borders' trading posts.

Except the above geographical advantages, Yunnan has many samenesses or similarities with Southeast Asian nationalities both on the ethnic origin and cultural traditions. The ethnic origins of majority nationalities in Southeast Asia, such as Thailand's Thai and Laos's Lao, Burma's Bamar and Cambodia's Khmer, are similar or same with many 
ethnic groups in Yunnan. The proximity of geoculture and blood relationship greatly promotes the exchange interaction between Yunnan and Southeast Asia for a long period of time.

For a long period, cross-border population movement in the border areas of Yunnan gives the priority to inside Yunnan and abroad borders flow. The spatial span of transnational floating population is relatively small, and personnel composition is also relatively single.

Since the 1990s, this kind of small-scale transnational population floating between villages has changed significantly. In this period, China began to positively adjust socioeconomic development model, pay more attention to regional socioeconomic balanced development, and implement the strategy of "Western Development" that eastern capital and technologies spread to western regions. With strengthening foreign economic relations, China also began to attach importance to regional economic cooperation with neighboring countries. The land access between China and Southeast Asian nations had been further developed by developing external traffic network. The industrial products, capital and technologies of mainland and costal areas had been further spread to neighboring countries through western border areas, while abundant natural resources of neighboring countries had been transported to the mainland and costal areas through border regions. In this process, logistics and capital flow among countries droved the population movement, accelerated the rapid growth of floating population, and occurred the unprecedented scale, degree and frequency of cross-border population movement. The transnational population movement of this period had larger spatial spans and more complex personnel composition, so these changes are largely derived from the combination between crossborder and domestic large-scale population floating. For border regions of Yunnan, the rise of border trade also attracts a large number of labor force flowing into border counties. And the labor force that be partly involved in cross-border population movement has become a main force of the recent floating.

Transnational population floating goes both ways. In addition to the above two major groups, the crossborder population movement of Yunnan also includes a number of foreigners. Because of various economic and socio-political reasons, these foreigners joined in this floating. Generally speaking, we can make the following division on the body of cross-border population movement and related population movement in border areas of Yunnan:

\subsection{Transnational migration of borders}

Due to the long-developed life pattern and cultural relationship by blood, border residents of Yunnan have continued to join transnational population movement in border areas. At present, the main form of border residents' transnational population movement give the priority to border trade, friends and relatives visit, and labor service.

There is a certain amount of regular border markets along borders of Yunnan. And hundreds of participants mainly consist of all ethnic borders on both sides of the border. In order to go in and out freely without applying for immigration formalities, residents from the other side should pay a small fee and hold valid documents such as a governmentissued Border Entry and Exit Permits.

Vietnam, Laos, Burma and Thailand are neighbors of border areas of Yunnan linked by mountains and rivers. Since ancient times, they have close communications and contacts. In addition, many ethnic groups that live on both sides of borders had 
the common ancestor, the same language and similar customs, therefore, the main form of transnational population movement for border residents is visiting friends and relatives. Because there are lots of overseas Chinese and their descendants in Shan State, Kachin State, Chiang mai and Chiang rai, many people go in and out of these regions to visit friends and relatives. For example, according to the statistics of county public security bureau in Tengchong county, Baoshan city, there were about 150 million average entry-exit persons in the late 1990s, and visiting friends and relatives accounted for about $8 \%$, 12000 persons.

Compared with neighboring countries, China has strong advantages in terms of human resource, capital and technology. Therefore, China has a number of borders which can legally join the transnational movement by labor export. Concerning about the transnational population movement of labors, relevant departments of local government are responsible for organization, trading and engineering companies, and other enterprises and institutions are responsible for recruitment, expatriation and implementation of production and operating activities about economic and foreign aid cooperation projects. Overseas industrial and mining enterprise, hospital and school are responsible for the recruitment of a few professionals. In the dry season of every year, relevant departments of Tengchong county government will organize 3000 rural surplus labor forces to undertake the road repairing, mining, logging and other labor service projects. Outside Pianma Port of Lushui county in Nujiang, there're about 2000 natives engaged in timber exploitation and transportation, as well as the construction and maintenance of forest highway. The status of borders who exit to work illegally is a common problem, and the number is large.

\subsection{The transnational migration of mainlanders}

Since the 1990s, with the intensification spread of China's population movement, internal migration has combined with transnational population movement in the frontier regions, and China finally formed the situation that the mainlanders were involved in the transnational population movement in border areas of Yunnan.

The form of participantion that mainlanders participate the transnational population movement in the frontier regions of Yunnan is various. People from coastal provinces in eastern China, such as Guangdong and Zhejiang, have the advantages in terms of information, capital, and technology, so they can participate in the activities of transnational commercial activities. For example, in the process of Sino-Burma border trade, businessmen from Guangdong are pretty active on wood, jade and other commercial activities.

Apart from few mainlanders exit through legal labor export, and there are quite a number of mainlands exit through illegal working or immigration. Illegal working mainlands mainly come from Sichuan, Chongqing, Hunan and other places.

International tourism is also the main entry-exit form of mainlanders. Data showed that there are millions of people going to Xishuangbanna through Daluo port of Menghai county travelling to Minela of Myanmar, or through Mohan port of Mengla County travelling to the south tower of Laos. Ruili, Wanding and Honghe river port located in Sino-Vietnam border of southeastern Yunnan are all international tourist hot spots. Every year, the number of entry-exit tourists can reaches 100000 people, and there're quite a number of mainlander in these tourists. 


\subsection{The transnational migration of foreigners}

Part of transnational floating population are engaged in commercial and labor service. Most of them are mainly distributed in the border of each ports, they are concentrated in Ruili of Dehong, Wanding, Baoshan city of Tengchong, Jinghong of Xishuangbanna, DaLuo, Mohan, Honghe river port, which are first-class or second-class ports in China. These mianlanders live on setting up stalls or shops, and having part-time work. In order to strengthen the management, the local government always tend to concentrate them together, forming a number of particular community whose main body are mainlanders. Among them, such as "Jewelry City" of Ruili city, the "Main Street" of Jiegao border trade zone in "Tourism Handicraft Street" of Jinghong city, as well as "Sino-Vietnam" street in Hekou county having a large number and scale, most of them are engaged in handicrafts, cosmetics, food and beverage service industry. According to concerning sectional statistics, at present, the total number of floating population staying in border areas of Yunnan is about 30000 or 40000 .

In the border areas of Yunnan, there are a number of mainlanders are entering the territory by informal channels. They are called "three non-" aliensillegal entry, illegal employment and illegal stay. According to the survey, there are a certain number of "three non-" aliens in almost every border counties of Yunnan Province. Among them, most aliens are in Baoshan, Dehong and Lincang, Simao and Xishuangbanna. In 2002, the government of Yunnan cleaned up about 3434 "three non-" aliens who are from neighboring countries by illegal entering, illegal residence and illegal employment. In 2011, the number increased to 14303 , the number of "three non-" aliens growing very fast. Those people most originate from the ethnic border, entering by illegal marriage, taking part-time jobs. It is estimated that the number of these people could now be about 100200 thousand people.

\section{Countermeasures and suggestions}

Transnational population movement involves different nations and regions, therefore, the governance of transnational population movement need to establish efficient action mechanisms and introduce mutual cooperations of all countries and regional organizations. Meanwhile, according to the current situation of border areas of Yunnan and China, the transnational population movement of Yunnan border areas has presently associated with internal population movement. Therefore, we also need to manage the border areas and external floating population in order to solve the transnational population movement issue in border areas of Yunnan.

\subsection{Establishing the regional cooperation} mechanism for the management of transnational migration

Because the management on transnational population movement involves the jurisdiction in different independent countries, the management of transnational population flow problems must depend on the close cooperation and coordination from judicial organs of regional countries. In recent years, with the strengthening the social and economic cooperation of China and southeast Asian neighboring countries, the judicial organs in combating transnational crime began to actively contact and cooperate. Nowadays, the regional cooperation framework mechanism gradually form and improve, we should promote countries, especially relevant management departments, to set up a more effective mechanism of regional cooperation. In 
terms of the border regions of Yunnan, we should focus on several aspects of work: Firstly, we should strengthen the cooperation with ASEAN (the association of south-east Asian nations ) countries. Secondly, at the national level, with the association of southeastern Asian nations (ASEAN) within the framework of "10 +1 "cooperation, establish and improve the mechanism of the cooperation between the countries, concluding combating transnational crime, border security cooperation, the judicial police of the interior of conventions, treaties and agreements, and formed the relevant cooperation organizations to carry out the relevant work; Thirdly, we should be actively to establish and join relevant international cooperation agreements and framework, and carry out in bilateral or multilateral cooperation governance of transnational migration and communication.

\subsection{Strengthening the management of borders}

At present, the three different border sectionsSino-Burma, Sino-Laos, and Sino-Vietnam have different situations. According to the " Two Methods" of state entry-exit management, Yunnan government has made three local administrative rules: Regulations on the Management of Overseas Borders' Entry-Exit Sino-Burma Region, Temporary Provisions on the Management of Chinese Personnel's Entry-Exit Sino-Burma Region, and Regulaions on the Management of Entry-Exit for Sino-Vietnam, Sino-Laos Borders, and Yunnan province public security department formulate the measures for the implementation of the rules to regulate border entry and exit management activities in Yunnan province.

On the other hand, the management on borders of Yunnan also faces special difficulties. Although China has signed an agreement on border management with the three countries bordering Yunnan Province, the situation of the management of different borders have obvious differences. In the three sections of borders, the number of the number of entry-exit people in the Sino-Burma border accounted for more than $80 \%$ of the number of entryexit people in Yunnan border, at the same time the management on Sino-Burma border is the most complicated. Due to the neighboring northern Burma being in the autonomous state in politics for a long time, this side of the Burma border's management is in a state of disorder for a long time. So it is difficult to effectively control the transnational population movement of this region. Therefore, we should strengthen the Sino-Burma border's management on the Chinese side, at the same time we need to actively work with Myanmar's related departments, to further promote bilateral border management of orderly under the treaty mechanism.

\subsection{The management of floating population in border regions}

At present, the cross-border population movement has presented a combination trend with internal migration, which put forward severe challenges to the social security of border areas. While in manage the border system, we need to take effective measures to manage the floating population of border regions. On the one hand, it is necessary to coordinate with countries, provinces and departments of counties so that foreigners can legally participate in the social economic activities of border areas and the crossborder population movement. Meanwhile, we must take relevant measures to limit and stop the blindness flowing into of foreigners as well. On the other hand, we have to strengthen the management of migrants flowing into the border areas, actively promote the management system of community floating 
populaiton in various counties and villages along the border areas, and focus on illegal entry-exit activities of foreigners.

\section{Acknowledgment:}

Financed by Yunnan Social Science Fund Youth Project in 2013:The Problems of "Three Non-" Aliens in Sino- Burma Border Region and its Governance, (QN2013022) ; Colleges and universities cooperation projects in yunnan province in 2013: The Research on the problems of "Three Non-" Aliens in Sino- Burma Border Region.

References

[1] Yunnan Yearbook Club: Yunnan Yearbook 2012, 2012.9.

[2] LuGang: Transnational Migration along the SinoBurma border region, Yunnan Nationality University Journal(Philosophy and Social SciencesEdition), 2006.6.

[3] Hu Ergui: Theory of Border Security Problems in Building a Harmonious Society — Research Evalution on Yunnan Border Security, Ideological Front No.4, 2007.

[4] Wang Xiaoping: The Governance Counter measures on Illegal Transnational Gambling and Criminal in Border Areas of Yunnan, Journal of Yunnan Police Officer Academy, No. 4, 2005. 